\title{
Infraclavicular Brachial plexus block in upper limb surgeries with local anaesthetic agent and dexmedetomidine as adjuvant for improving quality of analgesia
}

Feny Thakkar ${ }^{1}$, Vandana Parmar ${ }^{2 *}, V^{*}$ rinda Oza ${ }^{3}$ and Shilpa Sarathy ${ }^{4}$

*Correspondence: drvandanapithadia@yahoo.com

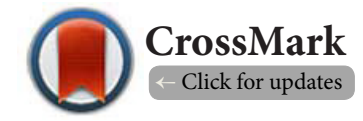

1Senior Resident Doctor, P.D.U. Medical College Rajkot, Guru krupa, Ravi ratna park 1 A, University road, Rajkot.
${ }^{2}$ Head of Department of Anaesthesiology, P.D.U. Medical College Rajkot, Gurukrupa 4A Shardanagar Society, University road, Rajkot.
${ }^{3}$ Associate professsor Department of Anaesthesiology, P.D.U. Medical College Rajkot, F-201, SadguruVatika, Maruti Nagar 2, Airport road,
Rajkot.
${ }^{4}$ rd Year Resident Doctor, P.D.U. Medical College Rajkot, 4 N Jamal's Plazzo, 47medavakkam main road,Keelkattalai,Chennai-600117, India.

\begin{abstract}
Context: To provide intraoperative and postoperative analgesia for upper limb surgeries the infraclavicular brachial plexus block (ICB) is very safe and reliable approach. $\alpha 2$ agonists are added to local anaesthetic agents as an adjuvant to extend the duration of nerve blocks.

Aims: Aim was to compare the efficacy of infraclavicular block with dexmedetomidine added to bupivacaine, xylocaine adrenaline mixture and bupivacaine, xylocaine adrenaline mixturealone with respect to duration of motor, sensory blockade and duration of analgesia in form of VAS (visual analogue scale).

Objective was to note the time for first rescue analgesic,sedation level of the patients and hemodynamic parameters.
\end{abstract}

Methods and material: A prospective randomized controlled study including 50 patients who were given vertical ICB using Peripheral nerve locator were divided into two equal groups. Control group (Group L) received Inj. Bupivacaine (0.5\%) $15 \mathrm{ml}+x y l o c a i n e ~ a d r e n a l i n e ~(1: 200000)(2 \%) 10 \mathrm{ml}+$ normal saline

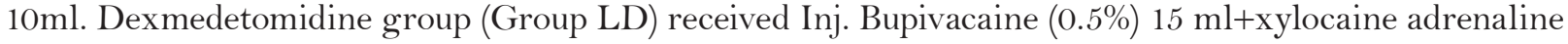
$(1: 200000)(2 \%) 10 \mathrm{ml}+$ normal saline $8 \mathrm{ml}+$ dexmedetomidine 1.5 microgram $/ \mathrm{kg}$ making total $35 \mathrm{ml}$.

For data analysis t test was applied.

Results: The onset of sensory and motor blockade were faster in LD group than $\mathrm{L}$ group $(\mathrm{p}<0.05)$. The duration of sensory and motor blockade and duration of analgesia were significantly longer in LD group $(\mathrm{p}<0.001)$. Patients in group LD were sedated with no adverse effects except bradycardia in three patients.

Conclusions: Dexmedetomidine as an adjuvant to local anaesthetic agents in infraclavicular block hastens the onset and prolongs the duration of sensory and motor blockade along with duration of postoperative analgesia.

Keywords: Infraclavicular brachial plexus block, dexmedetomidine, bupivacaine, lignocaine, postoperative analgesia

\section{Introduction}

Brachial plexus blocks are very useful alternative to general anaesthesia for upper limb surgeries. It is useful in patients with significant co-morbidities such as severe cardiovascular and respiratory diseases [1]. The two most common approaches of infraclavicular block are the medial approach also called vertical ICB and the lateral approach. Advantages of vertical ICB are less painful arm positioning, easily palpable landmarks, minimal risk of pneumothorax and vascular puncture [2-4]. Dexmedetomidine - a2- adrenergic receptor agonists has seda- 
tive, analgesic, sympatholytic and cardiovascular stabilizing effects with reduced anaesthetic requirements [5], prolongs the duration of the blockade and post-operative analgesia when added to local anaesthetic as an adjuvant in regional blocks. Onset of sensory and motor blockade, duration of sensory and motor blockade, duration of postoperative analgesia and haemodynamic parameters were noted.

\section{Materials and method}

The randomized double blind prospective study was carried out after obtaining ethics committee approval and written informed consent from the patient. All patients underwent a thorough pre-anaesthetic check-up which included history taking and examination. Routine investigations like complete blood count, blood sugar, blood urea, serum creatinine, Chest X-Ray, ECG were carried out for all patients. All patients were taught about pain scale(VAS scale) during their pre-operative visit.

Inclusion criteria includes all the cases between 15 and 65 years of age of either sex undergoing upper limb surgeries of ASA grade 1, 2 and 3.

Exclusion criteria includes patients with known coagulation abnormalities, known allergic reaction to drug, parental or patient refusal, systemic sepsis or local infection at the puncture point, injury at supraclavicular site or lymph node enlargement, neurological abnormalities such as brachial plexus injury, congenital anatomical deformities of upper limb or neck, shoulder or elbow joint replacement or any upper limb vascular surgeries with unduly prolong surgical duration and weight more than $75 \mathrm{~kg}$.

On the day of surgery, after taking patient inside operation room, IV line was secured and Inj. dextrose normal saline was started. Standard monitors like Electro Cardio Gram (ECG) leads, Non-Invasive Blood Pressure (NIBP) cuff, and pulse oximeter were applied and baseline parameters like Pulse Rate (PR); Systolic, Diastolic and Mean Blood Pressure (SBP, DBP, and $\mathrm{MBP}$ respectively), $\mathrm{SpO}_{2}$, sedation scores and pain score were recorded. Premedication was given for acid prophylaxis in form of inj.ondansetron $0.08 \mathrm{mg} / \mathrm{kg}$ and inj.ranitidinehydrochloride $1 \mathrm{mg} / \mathrm{kg}$. Patients were randomly allocated into two groups using a computer generated random number and concealed by sealed opaque envelopes.

Group L: Brachial plexus block will be given Infraclavicular approach with Inj. Bupivacaine $0.5 \%(15 \mathrm{ml})$ with xylocaine adrenaline (1:200000) (2\%) $10 \mathrm{ml}$ with normal saline $10 \mathrm{ml}$ making total $35 \mathrm{ml}$.

Group LD: Inj. Bupivacaine 0.5\% (15 ml) with xylocaine adrenaline (1:200000) (2\%) $10 \mathrm{ml}$ with normal saline $8 \mathrm{ml}+$ dexmedetomidine $1.5 \mathrm{microgram} / \mathrm{kg}$ making total $35 \mathrm{ml}$.

The patient and observer (who assessed the patient intra and post operatively) were not aware of the drug given. The drugs were prepared and administered by two different anaesthesia residents who were not involved in study to avoid biased results. The brachial plexus was located using standard peripheral neurostimulator (Stimuplex', B Braun) with 2- $\mathrm{Hz}$ and 1.0-mA. Figures 1 and 2 showing landmark and technique of block. The site that triggered muscular response to a stimulus equal to or lower than $0.5 \mathrm{x} \mathrm{mA}$ was located, and LA mixture was given in the increments of $5 \mathrm{ml}$ after fixing the needle

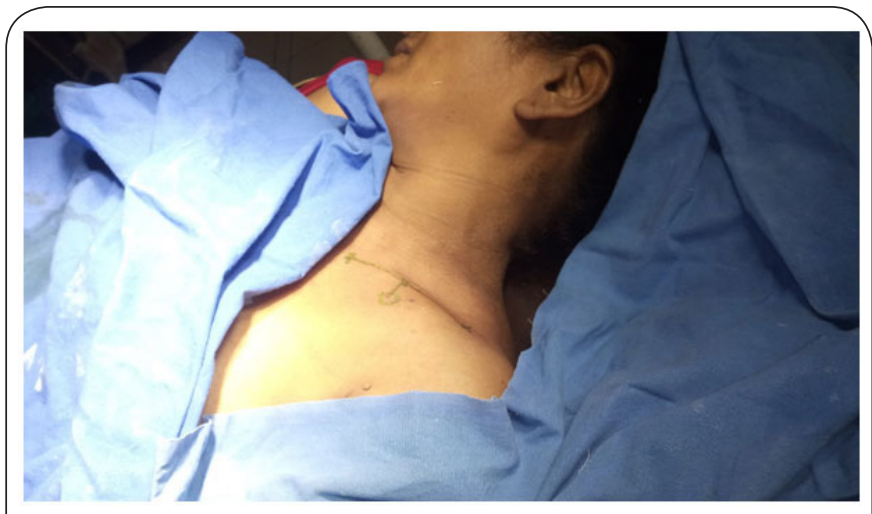

Figure 1. Landmark of Infraclavicular block.

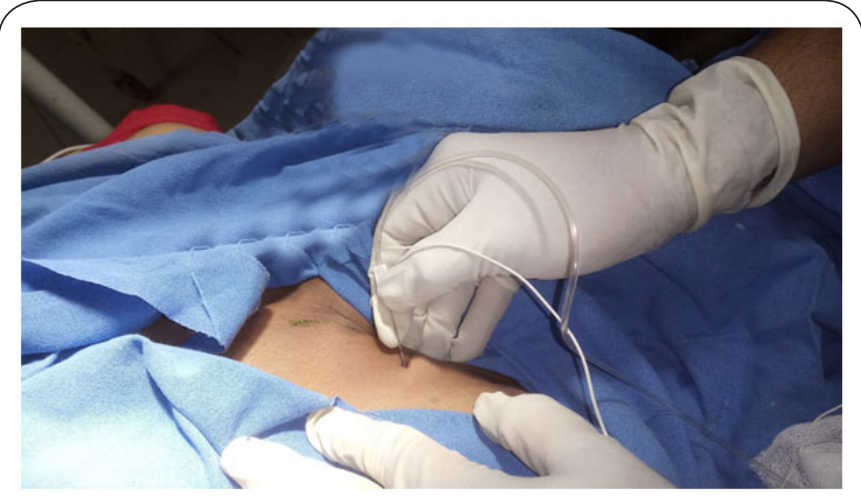

Figure 2. Technique of block.

and aspirating in between to avoid inadvertent intravascular injection. Heart rate, blood pressure, oxygen saturation was recorded before the procedure and there after every $5 \mathrm{~min}$ after the administration of block till half an hour, and then every $15 \mathrm{~min}$ till the end of procedure and postoperatively at $30 \mathrm{~min}, 1 \mathrm{hr}, 2 \mathrm{hr}, 4 \mathrm{hr}, 6 \mathrm{hr}$ and $12 \mathrm{hr}$. Simultaneously patient were monitored intraoperatively and postoperatively for sedation score, VAS (Visual analogue scale) score and any complications like nausea, vomiting, chest pain, coughing, convulsion, hypotension and bradycardia. Sensory and motor function were evaluated before the block and at 2, 5, 10, 15, 20,25 , and $30 \mathrm{~min}$ after the block, then every $15 \mathrm{~min}$ until $5 \mathrm{~h}$ post block, every 30 min until $12 \mathrm{hr}$ post block, and every 60 min until complete recovery. Intensity of post-operative pain was evaluated using VAS (visual analogue scale) with grade 0 (no pain) to 10 (worst pain). Analgesia was considered satisfactory if the score was 3 or less. If score was more than 4 , analgesia was judged unsatisfactory and rescue analgesia 
was administered in the form of inj. Diclofenac sodium and time for need of first analgesia was noted. Both groups will compared for total duration of analgesia (time interval between injections of drug in infraclavicular brachial plexus to rescue analgesic given), total duration of sensory blockade (Time interval between injection of drug and complete recovery of sensation) and total duration of motor blockade (Time i terval between injection of drug and complete recovery of motor power).

\section{Results}

Table 1 shows Demographic characteristic like age, sex, weight distribution and duration of surgery for both groups which were statistically comparable.

As shown in Table 2, mean onset of sensory $(9.24 \pm 1.738 \mathrm{Vs}$ $11.48 \pm 2.063$ minutes respectively) and motor block (14.12 \pm 2.04 Vs $16.16 \pm 2.544$ minutes respectively) was faster in group D L than in group $L$ (Table 2 ). It was statistically significant $(p<0.05)$.

Table 3 shows duration of block and duration of analgesia in both groups. The duration of sensory and motor blockade was significantly longer in group DL as compared to group L. The mean time to requirement of first rescue analgesic (VAS $>4$ ) in Group DL was 560.4 \pm 93.962 min., and in Group L was $423.6 \pm$ 62.907 min which was highly significant $(p<0.001)$ both clinically and statistically.

Figure 3 shows mean pulse rate just before block, just after block and; at $5 \mathrm{~min}, 10 \mathrm{~min}, 15 \mathrm{~min}, 20 \mathrm{~min}, 30 \mathrm{~min}$; and then every 15 minutes up to completion of surgery in both Groups. There was no statistically significant difference observed ex-cept between 90 to 150 minute, it was statistically significant $(p<0.05)$.
As shown in Figure 4, there was no statistically significant difference observed in the intraoperative mean blood pressure changes in both groups.

As per Figure 5, the mean sedation scores were more in Dexmedetomidine group compared to control group. However, the patients were easily arousable and co-operative all the time.

Table 4 shows mean postoperative pulse rate just after completion of procedure, 30 min, 1 hour, 2 hour, 6 and 12 hour interval in both Groups. Table 5 shows mean postoperative mean blood pressure changes. There was no statistically significant difference observed.

\section{Discussion}

The patients posted for upper extremity surgeries are preferably managed under brachial plexus block. Regional anaesthesia has many advantages over general anaesthesia like excellent postoperative analgesia, decrease in postoperative intensive care, decrease recovery time, shorter duration of hospital stay. In our study, elbow and below elbow surgical procedures we had preferred vertical infraclavicular block for several reasons:- Ability to perform block with patients head and arm in any position, avoidance of neurovascular structures of the neck, minimal risk of pneumothorax, it is ideal for continuous catheter placement and fixation as it is an area with little movement and therefore less chances of being displaced, successful musculocutaneous nerve block as compared to axillary block. It also provides excellent analgesia for an arm tourniquet.

Infraclavicular brachial plexus block (ICPB) was introduced

Table 1. Demographic Data.

\begin{tabular}{lllllll}
\hline & \multicolumn{2}{c}{ Group DL } & \multicolumn{2}{c}{ Group L } & \multirow{2}{*}{ P value } & Significance \\
\cline { 2 - 5 } & Mean \pm SD & CI & Mean \pm SD & CI & & \\
\hline Age & $40.08 \pm 14.47$ & $34.11-46.05$ & $36.92 \pm 11.09$ & $32.34-41.5$ & 0.39 & Not significant \\
Sex Male: Female & $17: 8$ & -- & $20: 5$ & -- & -- & -- \\
Duration of surgery & $99.6 \pm 29.3$ & $87.49-111.71$ & $90.6 \pm 31.6$ & $77.53-103.67$ & 0.30 & Not significant \\
\hline
\end{tabular}

Table 2. Onset of block.

\begin{tabular}{lllllll}
\hline & \multicolumn{2}{c}{ Group DL } & \multicolumn{2}{c}{ Group L } & \multirow{2}{*}{ P value } & Significance \\
\cline { 2 - 5 } & Mean \pm SD & CI & Mean \pm SD & CI & & \\
\hline Onset of sensory block & $9.24 \pm 1.738$ & $8.52-9.96$ & $11.48 \pm 2.063$ & $10.63-12.33$ & 0.000138 & Significant \\
Onset of motor block & $14.12 \pm 2.04$ & $13.27-14.97$ & $16.16 \pm 2.544$ & $15.11-17.21$ & 0.00309 & Significant \\
\hline
\end{tabular}

Table 3. Duration of block.

\begin{tabular}{lllllll}
\hline & \multicolumn{2}{c}{ Group DL } & \multicolumn{2}{c}{ Group L } & \multirow{2}{*}{ P value } & Significance \\
\cline { 2 - 6 } & Mean \pm SD & CI & Mean \pm SD & CI & & \\
\hline Duration of sensory block & $501.8 \pm 90.033$ & $464.64-538.96$ & $377.6 \pm 60.365$ & $352.69-402.51$ & $<0.001$ & Highly significant \\
Duration of motor block & $441.6 \pm 71.686$ & $412.01-471.19$ & $331.2 \pm 56.44$ & $307.91-354.49$ & $<0.001$ & Highly significant \\
Duration of analgesia & $560.4 \pm 93.962$ & $521.61-599.19$ & $423.6 \pm 62.907$ & $397.64-449.56$ & $<0.001$ & Highly significant \\
\hline
\end{tabular}



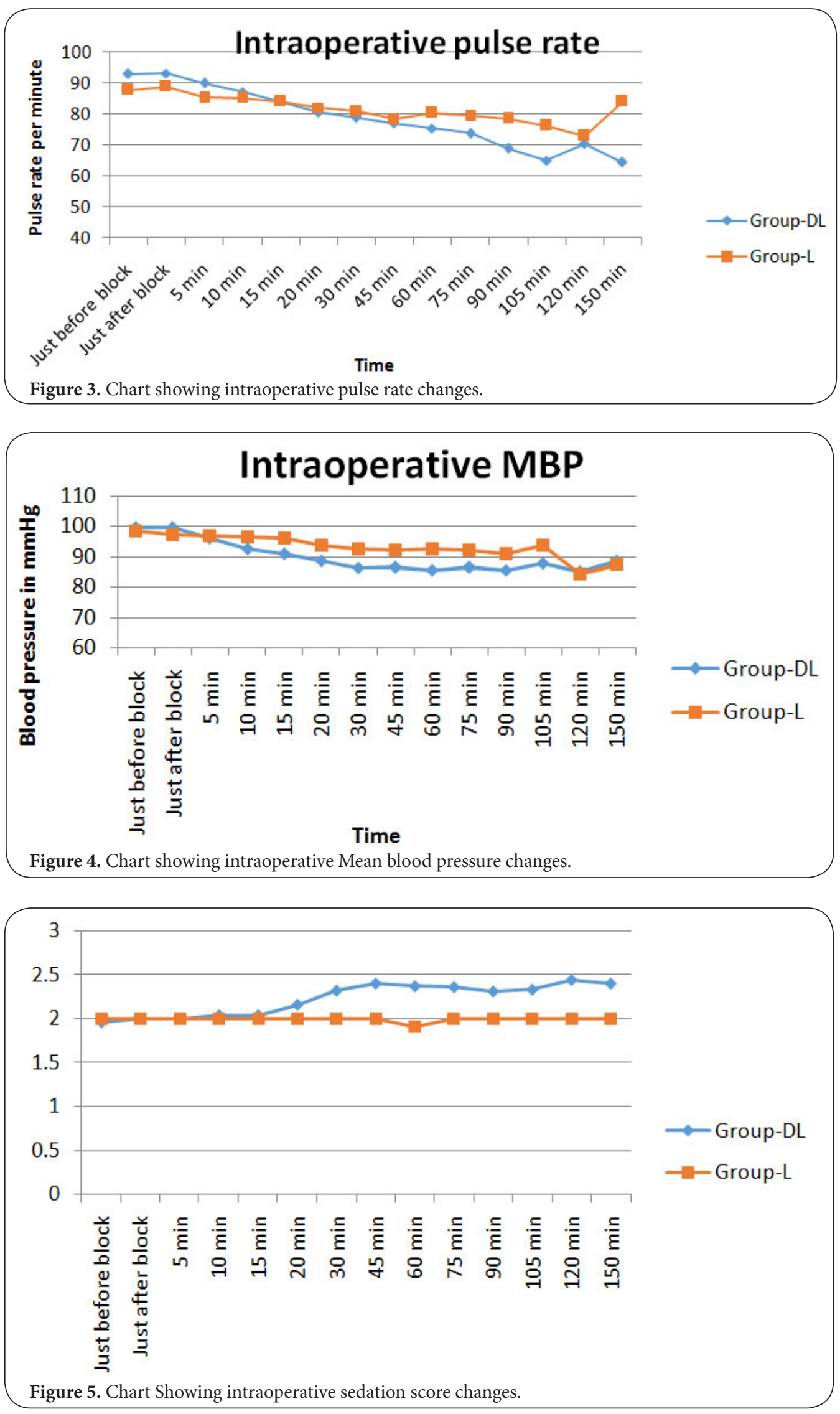
Thakkar et al. Journal of Anesthesiology \& Clinical Science 2018, http://www.hoajonline.com/journals/pdf/2049-9752-7-4.pdf

Table 4. Postoperative pulse rate changes.

\begin{tabular}{lllllll}
\hline & \multicolumn{2}{c}{ Group DL } & \multicolumn{2}{c}{ Group L } & \multirow{2}{*}{ P value } & Significance \\
\cline { 2 - 5 } & Mean \pm SD & CI & Mean \pm SD & CI & & \\
\hline 0 min & $74.88 \pm 8.87$ & $71.22-78.54$ & $78.8 \pm 9.91$ & $74.71-82.89$ & 0.14 & Not significant \\
30 min & $74.48 \pm 9.50$ & $70.55-78.41$ & $78.88 \pm 8.60$ & $75.25-82.35$ & 0.09 & Not significant \\
1 hour & $77.2 \pm 9.93$ & $73.10-81.30$ & $80.32 \pm 9.53$ & $76.39-84.25$ & 0.2 & Not significant \\
2 hour & $79.28 \pm 9.88$ & $75.20-83.36$ & $81.48 \pm 9.54$ & $77.57-85.39$ & 0.4 & Not significant \\
6 hour & $83.52 \pm 7.62$ & $80.37-86.67$ & $86.16 \pm 10.81$ & $81.70-90.62$ & 0.3 & Not significant \\
12 hour & $84.16 \pm 10.34$ & $79.89-88.43$ & $83.37 \pm 12.40$ & $76.76-89.98$ & -- & -- \\
\hline
\end{tabular}

Table 5. Postoperative Mean blood pressure changes.

\begin{tabular}{lllllll}
\hline & \multicolumn{2}{c}{ Group DL } & \multicolumn{2}{c}{ Group L } & \multirow{2}{*}{ P value } & Significance \\
\cline { 2 - 5 } & Mean \pm SD & CI & Mean \pm SD & CI & & \\
\hline 0 min & $89.04 \pm 9.87$ & $84.96-93.12$ & $93.06 \pm 8.64$ & $89.50-96.62$ & 0.13 & Not significant \\
30 min & $88.34 \pm 9.88$ & $84.26-92.43$ & $91.84 \pm 6.22$ & $89.28-94.40$ & 0.14 & Not significant \\
1 hour & $89.92 \pm 9.68$ & $85.92-93.91$ & $94.21 \pm 7.07$ & $91.30-97.12$ & 0.08 & Not significant \\
2 hour & $91.49 \pm 10.75$ & $87.05-95.93$ & $94.4 \pm 7.47$ & $91.30-97.12$ & 0.27 & Not significant \\
6 hour & $98 \pm 10.10$ & $93.83-102.17$ & $99.70 \pm 7.52$ & $96.60-102.80$ & 0.50 & Not significant \\
12 hour & $98.90 \pm 11.48$ & $94.17-103.65$ & -- & $42.74-82.54$ & -- & -- \\
\hline
\end{tabular}

in early $20^{\text {th }}$ century as an alternative to axillary and supraclavicular approaches. More common approaches are the medial approach also called vertical ICB around the middle of clavicle and the lateral approach around the coracoid process. Others include parasagittal and pericoracoid approaches. Adjuvants are added to local anaesthetics (LA) that prolong the duration of analgesia and have less adverse effects so that long surgeries can be conducted with a single shot brachial Plexus block and a need for continuous catheter is avoided. Local anaesthetics and various adjuvants have been evaluated in conjunction with it to prolong the period of analgesia in brachial plexus block.

Use of a peripheral nerve locator allows a precise localization of nerve plexus. It improves accuracy and success rate and decrease chances of nerve injury. Taboada M. Et al [6] studied that ultrasound guidance and nerve stimulation provide similar onset time, success rate, and duration of motor blockade for infraclavicular block. However, ultrasound guidance reduces the time required to perform the block. In our study extension or flexion type of fingers response on peripheral nerve locator is associated with higher success rate. In our study block was considered inadequate when sensory anaesthesia was not achieved 30 minutes after block. There are such eight cases in our study, and subsequent general anaesthesia was given. These patients then excluded from the analysis.

Dexmedetomidine a highly selective a-2-adrenergic receptor agonist, clinically effective doses lacks respiratory depression, but maintains its analgesic properties that may make it useful and safe adjunct. The proposed mechanisms are centrally mediated analgesia, a2B-adrenoceptor medi- ated vasoconstrictive effects, attenuation of the inflammatory response, and direct action on a peripheral nerve. Both Intravenous and perineural or intrathecal dexmedetomidine can prolong duration of analgesia. Doses varied between $0.5 \mu \mathrm{g} / \mathrm{kg}$ to $2 \mu \mathrm{g} / \mathrm{kg}$. In our study addition of $1.5 \mu \mathrm{g} / \mathrm{kg}$ dose of dexmedetomidine perineurally to local anaesthetic mixture in infraclavicular brachial plexus block hastens the onset of sensory and motor blockade without significant side effects. It was statistically significant $(p<0.05)$ (Table 2$)$. A total volume of $35 \mathrm{ml}$ of local anaesthetic agent was taken. Lomate P. et al [7] used $1 \mu \mathrm{g} / \mathrm{kg}$ dose of dexmedetomidine added to the local anaesthetics in infraclavicular brachial plexus block and found the significant extension in duration of blockade $(p<0.0001)$. Chaudhari $\mathrm{M}$ et al [8] added Dexmedetomidine to local anaesthetic agents in infraclavicular block and stated that it has faster sensory and motor blockade onset.

Waindeskar V, Jain A et al [9] studied dexmedetomidine as an adjuvant to bupivacaine in supraclavicular brachial plexus block and found mean duration time for sensory and motor blocks for group BD (Bupivacaine Dexmedetomidine) were $456.42 \pm 20.22$ and $418.6 \pm 32.46$ min respectively; but for the group B (Bupivacaine), the mean duration were $202 \pm 30.4$ and $172.4 \pm 41.26$ min respectively. There was no statistically significant difference observed in intraoperative mean pulse rate and mean blood pressure changes except between 90 to 150 minute when pulse rate was statistically significantly decreased in dexmedetomidine group $(p<0.05)$. Postsynaptic activation of $\mathrm{a}_{2}$ adrenoceptors in the central nervous system (CNS) inhibits sympathetic activity and thus can decrease blood pressure and heart rate. 
Thakkar et al. Journal of Anesthesiology \& Clinical Science 2018,

http://www.hoajonline.com/journals/pdf/2049-9752-7-4.pdf

doi: 10.7243/2049-9752-7-4

In our study three cases developed bradycardia (20\% decrease from baseline reading) which were managed by inj. glycopyrrolate/atropine sulphate. In dexmedetomidine group intraoperative systolic blood pressure decreases compare to control group but it was not statistically significant. Four cases developed hypotension ( $20 \%$ decrease from baseline reading) in which two were managed with Intravenous fluids and two require inj.mephentermine. There was no complications like pneumothorax, local anaesthetic drug toxicity, and respiratory paralysis in either of study groups. Kaur H., Singh G. et al [10] studied effect of dexmedetomidine as an adjuvant to levobupivacaine in supraclavicular brachial plexus block and observed a statistically significant difference $(P<0.05)$ in HR between two groups from 10 min after the block, which extended in the postoperative period up to $24 \mathrm{~h}$. Bradycardia $(H R<60)$ was observed in two patients in $B$ group but none of them required treatment. Agrawal P. et al [11] studied dexmedetomidine -as an adjuvant to lignocaine and bupivacaine in supraclavicular brachial plexus block and found that the patients in group dexmedetomidine maintained stable perioperative pulse rate, systolic blood pressure and diastolic blood pressure as compared to group $c(p<0.001)$.

Our study showed significant increase in sedation score in the dexmedetomidine group $(P=0.02)$ between 20 to 120 minute duration than in the control group. Locus ceruleus of the brain stem is the principal site for the sedative action of dexmedetomidine acting through a 2 adrenergic receptor. Patients were comfortable throughout the surgery with arousable sedative effects. This could be explained bythe fact that some amount of systemic absorption of drug could be present. Eskandr A et al [12] reported more sedation score observed in dexmedetomidine group $(D)$ in subtenon block in phacoemulsification cataract surgery $(P=0.022)$. In absence of supplemental IV sedation, 7 patients out of 25 in Group D were sedated, scoring $>3$ on Ramsay sedation scale.

In our study postoperative pulse rate, systolic, diastolic and mean blood pressure changes in both groups showedno statistically significant difference between both the groups.

Duration of analgesia was higher in dexmedetomidine group $560.4 \pm 93.962$ minutes vs $423.6 \pm 62.907$ minutes in control group which was highly significant $(p<0.001)$ both clinically and statistically. It also prolongs the time to first analgesic request, provides significantly lower postoperative VAS pain scores which was less than 3 . Injection diclofenac sodium as a rescue analgesic was given when VAS score more than 4.Our findings are comparable with other studies. All patients in both groups were haemodynamically stable. Ammar et al [13] studied ultrasound guided infraclavicular brachial plexus block using bupivacaine alone and then combined with Dexmedetomidine for pain control in upper limp surgeries and demonstrated enhancement of onset of sensory and motor blockade, prolonged duration of analgesia, increased duration of sensory and motor block, lower VAS pain scores, and reduction in supplemental opioid requirements in dex- medetomidine with bupivacaine group which is similar to our study. The easy availability and lack of significant side effects like respiratory depression makes dexmedetomidine an attractive choice as an adjuvant to local anaesthetics in infraclavicular brachial plexus block for prolongation of postoperative analgesia.

\section{Conclusion}

From observations and results, graphs and tables of my study, I conclude that the addition of $1.5 \mu \mathrm{g} / \mathrm{kg}$ dexmedetomidine as an adjuvant to local anaesthetics agent Inj.xylocaine with adrenaline (1:200000) 2\% (10) $\mathrm{ml}$ with Inj. Bupivacaine $0.5 \%$ $(15 \mathrm{ml})$ for infraclavicular brachial plexus block hastens the onset time and prolong the duration of sensory-motor blocks and also significantly prolongs the duration of postoperative analgesia and decreases requirement of opioid and nonopioid analgesics.

\section{Competing interests}

The authors declare that they have no competing interests.

Authors' contributions

\begin{tabular}{|l|c|c|c|c|}
\hline Authors' contributions & FT & VP & VO & SS \\
\hline Research concept and design & $\checkmark$ & $\checkmark$ & $\checkmark$ & -- \\
\hline Collection and/or assembly of data & $\checkmark$ & -- & -- & $\checkmark$ \\
\hline Data analysis and interpretation & $\checkmark$ & $\checkmark$ & $\checkmark$ & -- \\
\hline Writing the article & $\checkmark$ & $\checkmark$ & $\checkmark$ & $\checkmark$ \\
\hline Critical revision of the article & -- & $\checkmark$ & $\checkmark$ & -- \\
\hline Final approval of article & $\checkmark$ & $\checkmark$ & $\checkmark$ & -- \\
\hline Statistical analysis & $\checkmark$ & -- & -- & $\checkmark$ \\
\hline
\end{tabular}

Publication history

EIC: D. John Doyle, Case Western Reserve University, USA

Received: 14-Aug-2018 Final Revised: 25-Sept-2018

Accepted: 30-Sept-2018 Published: 11-Oct-2018

\section{References}

1. Fatma Gad El-rab Askar and Nawal Abdel Azeez Gad El-rab. Fentanyl as an adjuvant to bupivacaine in infraclavicular brachial plexus block. International Journal of Multidisciplinary Research and Development. 2017; 4:121-123.

2. Raj PP, Montgomery SJ, Nettles D and Jenkins MT. Infraclavicular brachial plexus block--a new approach. Anesth Analg. 1973; 52:897-904. | Article I PubMed

3. Kilka HG, Geiger $\mathrm{P}$ and Mehrkens HH. [Infraclavicular vertical brachial plexus blockade. A new method for anesthesia of the upper extremity. An anatomical and clinical study]. Anaesthesist. 1995; 44:339-44. | PubMed

4. Lanz E, Theiss $D$ and Jankovic D. The extent of blockade following various techniques of brachial plexus block. Anesth Analg. 1983; 62:558. I Article I PubMed

5. Elliott $S$, Eckersall $S$, Fligelstone $L$ and Jothilingam $S$. Does the addition of clonidine affect duration of analgesia of bupivacaine wound infiltration in inguinal hernia surgery? Br J Anaesth. 1997; 79:446-9. I Pdf | PubMed

6. Manuel taboada. Is ultrasound guidance superior to conventional nerve stimulation for coracoid infraclavicular brachial plexus block. 2014.

7. Prashant Lomate and Divakar Patil. Usefullness of dexmedetomidine as 
an adjuvant to local anaesthetics in infraclavicular brachial plexus block for prolongation of postoperative analgesia. 2015; 13:567-572.

8. Madhavi Sanjay Chaudhari and Naresh Dilipkumar Vaswani. Vertical infraclavicular block with Dexmeditomidine as an adjuvant to local anesthetics- multifaceted quality enhancement effort. 2016; 3:184-190. I Pdf

9. Waindeskar $\mathrm{V}$ and Jain $\mathrm{A}$. Alpha $\mathbf{2}$ agonist dexmedetomidine as an adjuvant to bupivacaine in supraclavicular brachial plexus block. 2016; 4. | Article

10. Kaur H, Singh G, Rani S, Gupta KK, Kumar M, Rajpal AS and Aggarwal $\mathrm{S}$. Effect of dexmedetomidine as an adjuvant to levobupivacaine in supraclavicular brachial plexus block: A randomized double-blind prospective study. J Anaesthesiol Clin Pharmacol. 2015; 31:333-8. I Article | PubMed Abstract | PubMed FullText

11. Pratiksha Agrawal. Dexmedetomidine-a novel drug, as an adjuvant to lignocaine and bupivacaine for prolonged post - operative analgesia in supraclavicular brachial plexus block. 2015; 4:823-834.

12. Ashraf M. Eskandr Dexmedetomidine is an effective adjuvant to subtenon block in phacoemulsification cataract surgery. 2014. | Article

13. Ammar AS and Mahmoud KM. Ultrasound-guided single injection infraclavicular brachial plexus block using bupivacaine alone or combined with dexmedetomidine for pain control in upper limb surgery: A prospective randomized controlled trial. Saudi J Anaesth. 2012; 6:109-14. | Article | PubMed Abstract | PubMed FullText

\section{Citation:}

Thakkar F, Parmar V, Oza V and Sarathy S. Infraclavicular Brachial plexus block in upper limb surgeries with local anaesthetic agent and dexmedetomidine as adjuvant for improving quality of analgesia.

J Anesthesiol Clin Sci. 2018; 7:4.

http://dx.doi.org/10.7243/2049-9752-7-4 